\title{
Basal Cortisol Levels and Cognitive Deficits in Human Aging
}

\author{
Sonia Lupien, ${ }^{1,3}$ André Roch Lecours, ${ }^{1,3}$ Isabelle Lussier, ${ }^{1,4}$ George Schwartz, ${ }^{2}$ N. P. V. Nair, and Michael J. \\ Meaney ${ }^{2}$ \\ 'Laboratoire Théophile-Alajouanine, Centre de Recherche du Centre Hospitalier Côte-des-Neiges, ${ }^{2}$ Aging Research \\ Program, Douglas Hospital Research Centre, Department of Psychiatry, McGill University, Montréal, Canada H4H-1R3 and \\ ${ }^{3}$ Faculté de Médecine and ${ }^{4}$ Département de Psychologie, Université de Montréal, Montréal, Canada H3C-1J7
}

\begin{abstract}
A group of 19 healthy elderly subjects previously shown to differ in terms of their cortisol levels over a 4 year period were administered a neuropsychological test battery assessing memory, attention, and language. Correlational analyses performed on various corticosteroid measures showed that the slope of the change in cortisol levels over time predicted cognitive deficits in this elderly population. Aged subjects showing a significant increase in cortisol levels with years and with high current basal cortisol levels were impaired on tasks measuring explicit memory and selective attention when compared to aged subjects presenting either decreasing cortisol levels with years or increasing cortisol levels with moderate current basal cortisol levels. We further showed that subjects presenting a decrease in cortisol levels with years performed as well as young healthy subjects with regard to cognitive performance. Thus, impaired cognitive performance was associated with recent evidence of hypothalamic-pituitary-adrenal (HPA) dysregulation and elevated basal cortisol levels. These results are consistent with recent animal studies showing the existence of subpopulations of aged rats that differ in HPA activity and cognitive performance. Finally, the pattern of cognitive results related to the cortisol history of subjects is in agreement with a role played by the hippocampus in age-related HPA dysfunction and cognitive performance.
\end{abstract}

[Key words: aged humans, cortisol, cognition, amnesic syndrome, hippocampus, memory]

In the rat, sustained exposure to elevated glucocorticoid levels in later life is associated with an increased loss of hippocampal neurons, accompanied by severe memory impairments. Indeed, adrenal glucocorticoid levels appear to predict the magnitude of hippocampal neuron loss and cognitive impairments (Landfield et al., 1981). In the Long-Evans rats, elevated plasma ACTH and corticosterone levels are apparent only in aged rats that show spatial memory deficits and not in aged rats that show normal spatial memory function (Issa et al., 1990). Indeed, aged,

\footnotetext{
Received June 8, 1993; revised Sept. 8, 1993; accepted Oct. 26, 1993.

This research was supported by grants from the American Alzheimer's Association and the National Institute of Aging (AG09488) to M.J.M., and from the Medical Research Council of Canada (MRCC) to N.P.V.N. S.L. and I.L. were supported by an MRCC graduate fellowship. The Aging Research Program of the Douglas Hospital is generously supported by ALCAN Canada Ltd.

Correspondence should be addressed to Sonia Lupien, Department of Psychiatry (0603), University of California at San Diego, 9500 Gilman Drive, San Diego, CA 92093-0603.

Copyright (C) 1994 Society for Neuroscience $0270-6474 / 94 / 142893-11 \$ 05.00 / 0$
}

unimpaired rats do not differ from young rats on measures of hypothalamic-pituitary-adrenal (HPA) activity (also see Levin et al., 1992; Sarrieau et al., 1992). These results strongly support the idea that increased HPA activity accounts, in part, for individual differences in the occurrence of age-related hippocampal pathology and memory deficits.

Existing studies in humans suggest that basal cortisol levels do not change with age (West et al., 1961; Friedman et al., 1969; Jensen and Blichert-Toft, 1971; Weitzman et al., 1971; Zumoff et al., 1974; Colucci et al., 1975; Lakatua et al., 1984; Linkowski et al., 1985; Sherman et al., 1985; Pavlov et al., 1986; Jensen et al., 1988; Sharma et al., 1989; Waltman et al., 1991). However, as in the Long-Evans rat, neuropathology in aged humans is associated with increased basal glucocorticoid levels (Davis et al., 1986; DeLeon et al., 1988; Dodt et al., 1991). The question that emerges here from the rodent data, is whether changes in HPA activity are associated with cognitive impairments in a population of normal aged humans.

The cognitive effects of elevated concentrations of corticosteroids in human populations have been studied in disorders affecting corticosteroid levels and using exogenous administration of the synthetic compound to healthy subjects. Mental disturbances mimicking mild dementia (such as decrements in simple and complex attentional tasks, verbal and visual memory, encoding, storage, and retrieval) have been described in depressed patients with hypercortisolism (Weingartner et al., 1981; Cohen et al., 1982; Rubinow et al., 1984; Roy-Byrne et al., 1986; Wolkowitz and Weingartner, 1988; Wolkowitz et al., 1990), and in steroid psychosis following corticosteroids treatment (Hall et al., 1979; Ling et al., 1981; Varney et al., 1984; Wolkowitz and Rapaport, 1989). The role played by the hippocampus in HPA dysregulation in human populations is suggested by recent studies in patients with Cushing's syndrome that report significant positive correlations between hippocampal formation volume and scores on verbal memory tests and significant negative correlations between hippocampal formation volume and plasma cortisol levels (Starkman et al., 1992). Moreover, many investigators have reported inverse relationships between mean $24 \mathrm{hr}$ cortisol levels and severity of cognitive decline in Alzheimer patients (De Leon et al., 1988; Oxenkrug et al., 1989; Martignoni et al., 1990). However, studies of endogenous disorders generally fail to discriminate the cognitive deficits related to HPA hyperactivity from those due to the underlying illness itself (Wolkowitz et al., 1990; Martignoni et al., 1992). Thus, most of the cognitive deficits associated with corticosteroids known today are derived from those observed during exogenous administrations of synthetic glucocorticoids 
to healthy subjects. In general, it is reported that corticosteroids impair selective attention, that is, the ability to discriminate relevant from irrelevant information, which is in accordance with electrophysiological findings that acute administration of cortisol to human subjects reduces the average evoked potential response to relevant but not to irrelevant stimuli (Kopell et al., 1970). These findings are also consistent with studies showing that glucocorticoids can impair neuronal electrophysiology (Joels and DeKloet, 1989; Kerr et al., 1989) and hippocampal longterm potentiation (LTP; Diamond et al., 1992; S. R. Bodnoff, D. M. Diamond, G. M. Rose, and M. J. Meaney, unpublished observations).

The role of the hippocampal formation in human learning and memory is now well established (for a complete review, see Squire, 1992). More importantly, studies report that the hippocampus is essential for a specific kind of memory, notably declarative (Cohen and Squire, 1980) or explicit memory (Graf and Schachter, 1985). In contrast, the hippocampus is not essential for nondeclarative or implicit memory (Gaffan, 1974; Hirsh, 1974; Squire, 1982, 1987; Cohen, 1984; Thompson, 1986; Schacter, 1987; Butters et al., 1990). Explicit memory refers to conscious or voluntary recollection of previous information, whereas implicit memory refers to the fact that experience changes the facility for recollection of previous information without affording conscious access to it. Thus, this somewhat specialized role of the hippocampus could serve as the basis for specific hypotheses regarding the effects of long-term exposure to corticosteroids on human cognition.

We have recently analyzed the results of a longitudinal study performed over a 4 year period on healthy aged subjects which revealed that aged humans show variable patterns of HPA activity in later life. Over all subjects, there were no major changes in basal cortisol levels. However, the longitudinal basal cortisol data revealed the existence of distinct subgroups of elderly subjects (S. Lupien, A. R. Lecours, G. Schwartz, M. J. Meaney, and N. P. V. Nair, unpublished observations). Simple regression analysis on plasma cortisol levels for each subject was conducted with year as the independent variable and cortisol concentration at each year as the dependent variable. The slope of the regression line then served as the measure of the cortisol history per subject. A preliminary distinction was drawn between aged subjects showing an elevation of cortisol levels with years $(\sim 84.6 \%$ of the population) and subjects showing a decline of cortisol levels with years ( $\sim 15.4 \%$ of the population). A second classification was made within the first group, between individuals who have reached elevated basal cortisol levels comparable to those gencrally obscrved in Alzheimer patients (15.0 $\pm 0.4 \mu \mathrm{g} /$ $\mathrm{dl} / \mathrm{hr} ; \sim 37.9 \%$ of the group), and individuals who have kept moderate basal cortisol levels over the years $(10.8 \pm 0.2 \mu \mathrm{g} / \mathrm{dl} /$ hr; $\sim 46.7 \%$ of the group). Neither the age of the subjects, nor their subjective complaints on the SCL-90 questionnaire, a selfreport rating scale measuring personality dimensions such as depression and anxiety, accounted for these results. Moreover, the groups did not differ in plasma corticosteroid binding globulin levels, and across all subjects, free and total cortisol levels were highly correlated $(r>0.90)$.

The first goal of this study was to assess a broad range of cognitive functions in a subpopulation of this longitudinal study. Sensitive neuropsychological measures were used in order to determine whether there are any cognitive deficits related to measures of corticosteroids in an elderly population and if so, to identify which cognitive components are affected. The second goal of this study was to determine whether a static (single recent measure) or a dynamic measure of cortisol levels (cortisol slope or the general mean across years) would be the best predictor of cognitive deficits. We first postulated that if long-term exposure to progressively elevated titers of corticosteroids (rather than "static" or "acutely" elevated levels of corticosteroids at one point of an individual's life) is the major determinant of hippocampal damage, the cortisol slope of subjects would be the better predictor of cognitive deficits. With regard to the nature of these cognitive deficits, we further hypothesized that if long-term HPA dysfunction is selectively associated with hippocampal pathology and not merely with advanced age (Issa et al., 1990), then the cognitive picture related to elevated cortisol slopes would resemble that of the amnesic syndrome, that is, would be only characterized by deficits in explicit memory with no deficits in implicit memory or in any other cognitive spheres tested.

\section{Materials and Methods}

\section{Subjects}

Eleven male and 8 female French-speaking subjects ranging from 60 to 80 years participated in this study. Men and women were of equivalent age $($ men $=70.3$ years \pm 6.3 ; women $=68.4$ years \pm 5.5$)$ and education level $($ men $=10.9$ years \pm 3.0 ; women $=11$ years \pm 2.8$)$ and were part of a broader population of aged healthy subjects being tested on various hormonal measures at the Douglas Hospital Research Center in Montreal. The inclusion criteria for the neuropsychological assessment were as follows: French as the maternal language, no history of head trauma or cerebral vascular accident, no alcohol abuse or use of drugs that could interfere with performance, and no general anesthesia in the last year.

\section{Cortisol measures}

For the cortisol study, the status of the subjects was determined by a complete physical examination, ECG, EEG, CAT scan, and a battery of laboratory tests for kidney, liver, and thyroid functions, hemogram, and vitamin B12 and folate levels. Informed consent was obtained from all subjects. All subjects were sampled for a $24 \mathrm{hr}$ period using an indwelling forearm catheter kept patent with a $0.3 \%$ heparin saline solution. Throughout the course of sampling, illumination was maintained at 300 lux during the "daytime" (0700 to 2300) and at 50 lux during the "nightime" (2300 to 0700). Blood samples were taken each hour, centrifuged at $2500 \mathrm{rpm}$ for $10 \mathrm{~min}$ at $0-4^{\circ} \mathrm{C}$, frozen, and stored at $-20^{\circ} \mathrm{C}$ until assayed.

Measures of cortisol levels were obtained once a year, beginning in early 1987 until late 1991. Some subjects participated throughout the entire course of the study while others joined it at various moments between the first and last year. This gave rise to a population composed of individuals having been measured twice or more. Preliminary analyses performed on the pattern of cortisol levels over the years as a function of times of measurement revealed that the pattern of increase or decrease in subjects was consistent among those measured for longer period (S. Lupien, A.R. Lecours, G. Schwartz, S. Sharma, M.J. Meaney, and N.P.V. Nair, unpublished observations). Each subject has been seen during the same month for each consecutive year. Cortisol levels in plasma were determined using an RIA kit (New England Nuclear Corp., Boston, MA) with cortisol ${ }^{125} \mathrm{I}$ as tracer and a cortisol antibody that binds moderately with corticosterone $(\sim 15 \%)$, but less than $4 \%$ with 11-deoxycortisol, 17a-hydroxyprogesterone, 11-deoxycorticosteronc, prednisone, cortisone, or progesterone. The minimum sensitivity of the assay is $200 \mathrm{pg} / 100 \mathrm{ml}$, with inter- and intraassay variability of $5 \%$ and $3.5 \%$, respectively.

Three cortisol measures were used for each subject and correlated with neuropsychological measures. The cortisol slope was first calculated using a simple regression analysis as described earlier, and served as an estimate of the "cortisol history" of subjects since the magnitude and the direction of the slope determine the importance of the cortisol augmentation or decline with years. The longitudinal measures of each subject were thereafter averaged across years, giving another estimate of the cortisol status that takes into account variability of cortisol levels across years (thereafter "averaged-24 hr"). Finally, the plasma cortisol level taken on the last year of the study (1991) was used (thereafter 
Table 1. Longitudinal data for mean cortisol levels for the three subgroups of elderly subjects

\begin{tabular}{|c|c|c|c|c|c|c|}
\hline \multirow[b]{2}{*}{ Group } & \multicolumn{4}{|c|}{ Year of measurement } & \multirow[b]{2}{*}{ Slope } & \multirow{2}{*}{$\begin{array}{l}\text { Averaged- } \\
24 \mathrm{hr}\end{array}$} \\
\hline & $1987-1988$ & $1988-1989$ & $1989-1990$ & $1990-1991$ & & \\
\hline PSE. 1 & 8.60 & & 8.82 & 13.52 & 2.45 & 10.31 \\
\hline PSE. 2 & 8.63 & 6.99 & 11.18 & 14.93 & 2.31 & 10.43 \\
\hline PSE.3 & 5.06 & 10.3 & 12.84 & 14.45 & 3.08 & 10.66 \\
\hline PSE.4 & & 8.65 & 12.15 & 14.15 & 2.75 & 11.65 \\
\hline PSE. 5 & & & 10.62 & 12.85 & 2.23 & 11.74 \\
\hline PSE. 6 & 13.38 & 7.05 & 13.51 & 15.73 & 1.35 & 12.42 \\
\hline PSE.7 & & & 15.02 & 15.46 & 0.44 & 15.25 \\
\hline PSE. 8 & & & 10.63 & 14.16 & 3.52 & 12.40 \\
\hline PSM.1 & & 9.12 & 8.48 & 10.41 & 0.65 & 9.34 \\
\hline PSM.2 & & 9.75 & & 9.83 & 0.09 & 9.79 \\
\hline PSM.3 & & & 10.18 & 10.40 & 0.23 & 10.29 \\
\hline PSM.4 & & 8.05 & 11.70 & 11.90 & 1.93 & 10.55 \\
\hline PSM.5 & & & 10.31 & 10.81 & 0.50 & 10.56 \\
\hline PSM.6 & & 10.51 & & 11.33 & 0.82 & 10.92 \\
\hline NS. 1 & & & 11.46 & 10.63 & -0.84 & 11.05 \\
\hline NS. 2 & & & 14.65 & 11.56 & -3.09 & 13.11 \\
\hline NS.3 & 8.67 & 10.61 & 10.98 & 7.54 & -0.30 & 9.45 \\
\hline NS.4 & & 16.35 & 14.68 & 14.27 & -1.04 & 15.1 \\
\hline NS.5 & & & 23.70 & 15.85 & -7.85 & 19.78 \\
\hline
\end{tabular}

Last-24 $\mathrm{hr}$ (1990-1991), cortisol slope, and averaged-24 hr measures are also presented for each subject.

"last-24 hr") in order to see if "static" cortisol levels would be better correlated to neuropsychological measures than one or both of the other cortisol measures. Table 1 presents the mean cortisol levels longitudinally as well as the three cortisol measures for each subject.

\section{Neuropsychological measures}

During 1991, a double-blind neuropsychological assessment was conducted for all 19 subjects in three sessions lasting about $1.5 \mathrm{hr}$ each. Sessions were never more than 1 week from each other and were all during the afternoon, beginning at 1330 in order to control possible differential effects of the circadian pattern of cortisol on cognition. Neuropsychological tools were developed in order to test three cognitive spheres, namely, memory, attention, and language. For the sake of clarity, each test will be described under the general heading to which it is related.

\section{Memory}

Short-term memory. Short-term memory refers to a system that temporarily retains information while it becomes incorporated into a permanent long-term store. This form of memory was tested by a digit span test. The subject listened to a series of numbers ranging from two to nine digits and was instructed to repeat them orally in the given order immediately afterward. The digit span of each subject was defined as the number of stimuli the subject could repeat correctly in $50 \%$ of cases.

Long-term memory/immediate versus delayed recall. The paragraph recall, visual reproduction, and associate learning subtests of the Wechsler memory scale (WMS; Wechsler, 1969) were given to the subjects in order to have a general picture of long-term memory for immediate and delayed recalls. Performance on each test was measured relatively to the norms proposed by the WMS. Individual scores on these subtests and on the similarities and comprehension subtests of the OttawaWechsler intelligence scale are presented in Table 2.

Long-term memory/explicit versus implicit. Explicit memory was assessed by a cued recall test and implicit memory by a word completion test (Lussier and Perelz, 1991), both derived from the same experimental list that was made of 12 imageable and concrete word pairs following Lyons's (1976) criteria, which were selected from Freibergs's (1968, 1970) word free association norms for Quebec French. The nonassociative nature of the word pairs is generally the primary determinant of explicit memory deficit; thus, the list was composed of six moderately related word pairs (related pairs) and six unrelated word pairs (unrelated pairs). The related pairs corresponded to the third associate in the free association norms, to minimize guessing in the cued-recall task. The nonassociative nature of the pairs was verified by asking 24 subjects ( 12 young and 12 old) to give the first word that came to mind when presented with one of the words from a pair. None of the words from the unrelated pairs generated the expected words. The unrelated pairs were constructed so as to be matched to the rclated pairs in terms of word frequency, word length, and grammatical category. Presentation of material and response recording were monitored by a Macintosh SE computer. For the explicit memory task, the subject was presented with the list of word pairs that he had to read aloud. The list was presented twice in a different order immediately. Following each presentation, the subject made a cued recall where he had to recall a member of a pair when presented with the other. Following the cued recall test, the subject was presented with a distractory task of word fragment completion (e.g. $\mathrm{R}-\ldots-\mathrm{E}$ ), which lasted $10 \mathrm{~min}$. The goal of this distractory task was to mask the connection between the explicit and implicit conditions and, at the same time, to create an interference to prevent recency effects on the completion task to follow. Implicit memory was thereafter tested by a word completion task. Subjects were instructed to complete each presented syllable as fast as possible and with the first word that came to mind. The subjects were told that this was a completely different test. No restriction was imposed as to the category of word that could be given as a completion. The first syllable was used as a cue, instead of the first three letters that are more traditionally used, because, in French, it corresponds to a perceptual speech unit (Mehler, 1981). After being presented with an example, the subject had to complete 72 such syllables. Among these, 24 corresponded to the first syllable of each word of the pairs learned previously, while 24 others corresponded to the first syllable of words from a second list that was given for explicit and implicit memory to another group of 19 elderly subjects in order to have a baseline for implicit memory. The 24 last syllables were randomly chosen. Thus, only one-third of the cues corresponded to the material presented in the studied list. This was again done to prevent subjects from making a connection between the presented syllables and the words that were presented previously. Completion of the 24 syllables of the second list by 19 elderly subjects $(8$ men and 11 women, mean age of 67 years; mean scolarity of 10.2 years) permitted the establishment of a baseline score, in order to have an estimate of completion that is attributable to chance. This estimate was the number of syllables completed with the words from the experimental list without learning. The dependent measure for the cued-recall task was the number of words correctly recalled, while for the implicit task it corresponded to the number of words generated with prior exposure minus number of words generated without prior exposure (baseline). 
Table 2. Description of subjects and performance on standard memory and intelligence tests

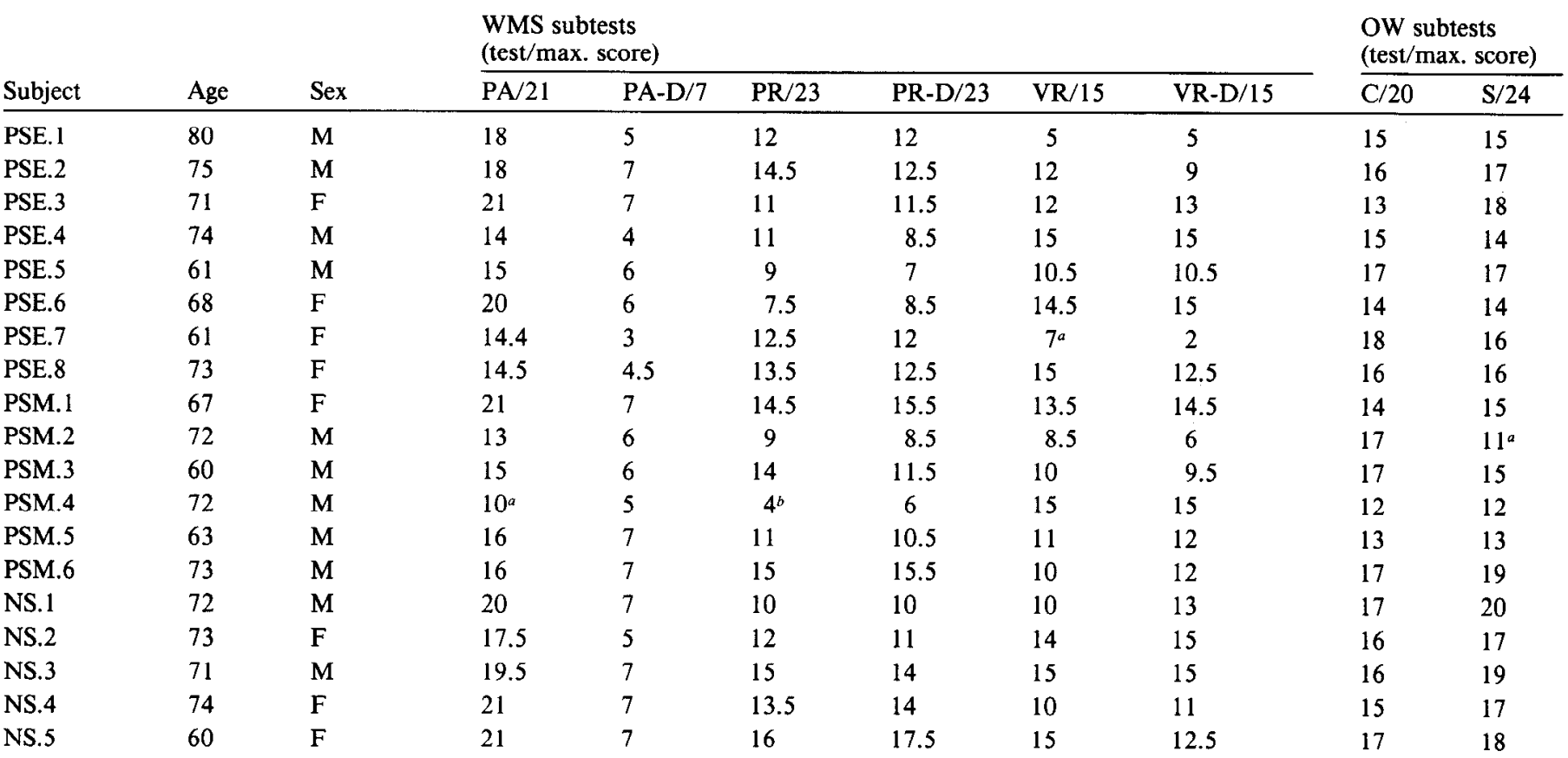

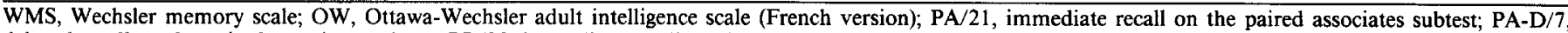

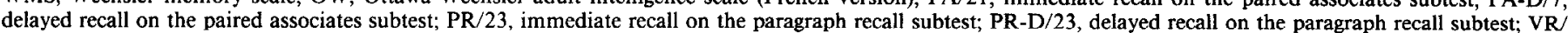

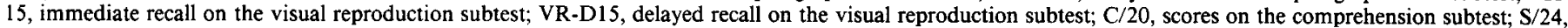

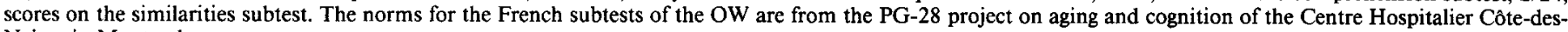
Neiges in Montreal.

"Scores within 1 SD from the normal range.

"Score within 2 SDs from the normal range.

\section{Attention}

Selective attention. Selective attention refers to the ability to discriminate relevant information from irrelevant one (Rabbitt, 1964). This was measured by a visual search task designed in relation to Treisman's feature integration theory (Treisman, 1982, 1983). Subjects had to search for a target specified by a conjunction of features (color and shape). The target was a black X, whilc thc distractors were white Xs, black Os, and white Os. The stimuli were displayed on a Macintosh SE computer. A two-button response box was used for response production, and the experiment was run in a dimly lit room. A white-fixation stimulus was shown at the center of the display screen between trials. The number of stimuli displayed on a single trial was $1,4,7$, or 10 . The target was present on half the trials and absent on the other half. There were 20 trials per number of stimuli that were presented on two blocks of 80 trials, for a total of 160 trials. The fixation point was presented for 1 sec and was immediately replaced by the display, which remained on the screen until the subject responded by pressing the yes/no button. Error rates and reaction times (RTs), which were triggered by the onset of the search array and stopped when a response key was pressed, were recorded by the computer. The median RTs and error rates of subjects were computed for each factor (target presence and number of stimuli).

Divided attention. Divided attention refers to the capacity limitations of information processing and is concerned with the quantity of information to which attention can be allocated at any given moment (Craik, 1977). This form of attention was measured using a paradigm designed in relation to Craik's theory of capacity limitations (Craik, 1977). The two tasks used were a digit span (see above) and a visual detection task. Subjects were first matched on each single task performance (100\% for the digit span task and $60 \%$ and $90 \%$ for the visual detection task) and then submitted to the dual-task condition where they had to perform both tasks simultaneously. The visual detection task involved the presentation of square matrix patterns on a Macintosh SE computer. Each pattern consisted of four squares disposed in a crossed-like manner, on a white background. On each trial, two of the squares were randomly filled with two black crosses, and two arrows pointed or not in the direction of the two squares containing the two crosses. The task of the subject was to detect, as fast as possible, whether the two arrows were pointing in the direction of both squares containing the crosses. Each trial was followed by a mask composed of the four squares filled by the four crosses and directed to by the four arrows. The complexity of the visual detection task was manipulated by varying stimulus duration. Each level of complexity of the visual detection task were performed twice on the dual-task condition. Afterward, both single-task performances were reassessed in order to prevent practice effects across the experiment. These different orders of presentations gave rise to 60 trials in the $60 \%$ and $90 \%$ conditions for both single and dual-task conditions. Error rates and RTs were computed for each subject. The measures of divided attention referred to the performance drop on the digit span and on the visual detection task for both lcvels of complexity when the two tasks were performed simultaneously.

\section{Language}

Verbal fluency. Verbal fluency can be defined as the ability to retrieve members belonging to a specified category within a limited timc pcriod (Rosen, 1980). The test used in the present experiment was comprised of six category criteria and six formal criteria. The formal criteria required giving words that began with a specified letter while the category criteria required giving words that were members of a category such as animal names. Each type of criterion was divided into three levels of retrieval complexity as assessed by the number of items in French dictionary related to each criterion (Sabourin, 1988). Subjects were given a letter or a category on each trial, and were asked to generate as many words as possible during a 2 min period. The subjects were informed to give only substantive words. The mean number of reported items for each type of criterion served as the measure of verbal fluency capacities.

Picture naming. Picture naming refers to a process called "lexicalization" and describes the capacity to attach meaning to words (Lachman and Lachman, 1980). The picture naming test used in the present context consisted of 80 outline drawings (Metz-Lutz et al., 1991), which were presented on a Macintosh SE computer. The computer displayed one figure at a time and subjects were asked to supply the name of the object in a microphone linked to the computer, which permitted to record 
RTs to each stimulus. All spontaneous responses were recorded verbatim. Median RTs of correctly named stimuli were first calculated. An inter-judges method was adopted for the scoring of responses. A response was accepted only if it was scored unanimously in this way. The percentage of correct responses then served as the second measure of subject's performance for the picture naming task.

\section{Statistical analyses}

Correlational analyses were performed on each three cortisol measures (cortisol slope, averaged-24 $\mathrm{hr}$ and last-24 hr) in relation to each neuropsychological task (1) to assess if any cognitive performance would be related to cortisol measures and if so (2) to determine which cortisol measure would be the best predictor of these cognitive performances. In order to decrease the probability of a type 1 error, we used a highly conservative statistical criteria. In one-tailed Pearson's table, a 0.05 significant criterion is representative of \pm 0.39 correlation coefficient. However, in behavioral science research where there is increasing probability of type 1 errors, Cohen and Cohen (1983) suggest that a \pm 0.50 correlation coefficient meets the conventional definition of a large effect. We thus decided to use this significance criterion which, in Pearson's table, represents a 0.02 coefficient. In each case where a significant correlation would be reported between a cortisol and a neuropsychological measure, appropriate analyses of variance (ANOVAs) would be performed by dividing subjects into groups relative to their cortisol concentrations or histories.

\section{Results}

Correlational analyses

Table 3 shows the correlation coefficients for all cortisol and neuropsychological measures. First, the only cognitive functions that were significantly related to corticosteroid measures in this elderly population were those measured by the explicit memory and selective attention tasks. Second, these effects occurred only in relation to the cortisol slope measure of subjects. A 0.60 negative correlation was reported for the cortisol slope measure on the explicit memory task, which revealed that subjects with high positive cortisol slopes performed less well than subjects with low positive or negative cortisol slopes. The same pattern of results cmerged from $\mathrm{RT}$ data on the selective attention task. The 0.57 positive correlation reported between the cortisol slope measure and the general RTs performance revealed that subjects with high positive cortisol slopes had longer RTs than subjects with low positive or negative cortisol slopes. Thus, the cortisol slope measure was the only predictor of cognitive performance since there was no significant correlation between current basal cortisol levels and any measure of cognitive performance.

In order to measure qualitative differences in subcomponents of explicit memory and selective attention as a function of cortisol slopes, all 19 subjects were divided into three groups, following the longitudinal criteria described earlier. A first group $(n=8)$ presented positive slope and elevated basal cortisol levels on the last year of the study $(14.4 \pm 0.3 \mu \mathrm{g} / \mathrm{dl} / \mathrm{hr})$ that were comparable to those generally observed in Alzheimer patients [called the positive slope elevated (PSE) group]. A second group $(n=6)$ presented positive slope but had moderate cortisol levels on the last year of the study [10.8 $\pm 0.3 \mu \mathrm{g} / \mathrm{dl} / \mathrm{hr}$; called the positive slope moderate (PSM) group], and a third group ( $n=$ 5) presented overall negative slope [current cortisol value: 11.97 $\pm 1.5 \mu \mathrm{g} / \mathrm{dL} / \mathrm{hr}$; called the negative slope (NS) group].

Explicit/implicit memory. Although only the explicit component of the memory task reached significance level on the correlational analyses, the implicit memory data were also analyzed since both components were part of the same experiment, and some of the effects on explicit memory could potentially be explained by those on implicit memory (Lussier and Peretz,
Table 3. Pearson's correlation coefficients for neuroendocrine and neuropsychological measures in a group of 19 aged healthy subjects

Neuroendocrine measures

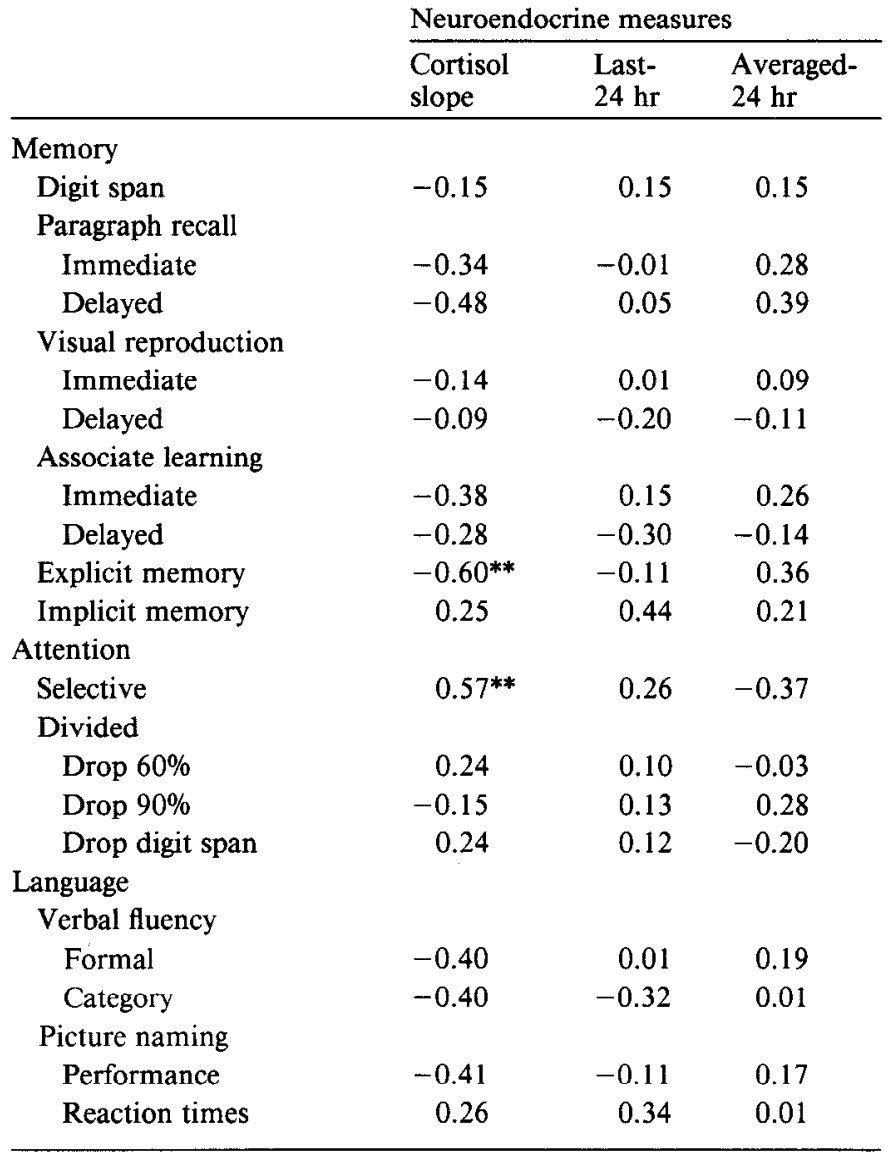

1991). However, since they did not share the same mcasurement scale (see above), separate ANOVAs were performed for each data set. A group $\times$ association (related vs unrelated pairs) ANOVA performed on the cued recall task revealed significant effects of both group $[F(2,16)=11.88 ; p<0.001]$ and association $[F(1,16)=46.84 ; p<0.001]$, as well as a marginally significant interaction between these two factors $[F(2,16)=3.26$; $p=0.06]$. Since precise hypotheses were related to the direction of this interaction, simple effects were analyzed and showed that groups did not differ on the recall of related pairs whereas they did on the recall of unrelated pairs $(p<0.01)$; the PSE group recalled significantly less unrelated pairs than the NS group, which did not differ from the PSM group. As presented in Figure 1, the PSM group fell between the PSE and NS groups on the recall of unrelated-pairs with a performance closer to that of the PSE group than to that of the NS group. Moreover, this interaction revealed that for both the PSE and PSM groups, related pairs were better recalled than unrelated pairs, whereas the NS group did not exhibit this effect. With regard to the word completion task, a preliminary unpaired two-tailed $t$ test was performed on the number of word given as a function of status (implicit vs baseline). This analysis revealed, as expected, that implicit scores were significantly higher than the baseline $[t(36)$ $=2.578 ; p<0.00$ ], thus showing evidence of implicit memory. A group $\times$ association ANOVA was then performed on the implicit measure (number of words generated with prior exposure minus baseline) and did not reveal any significant effect. 
Figure 1. Mean correct recall on the cued recall task for related and unrelated word pairs for subjects of the PSE, PSM, and NS groups and for 10 young healthy subjects. SE bars not shown were all under $4 \%$.

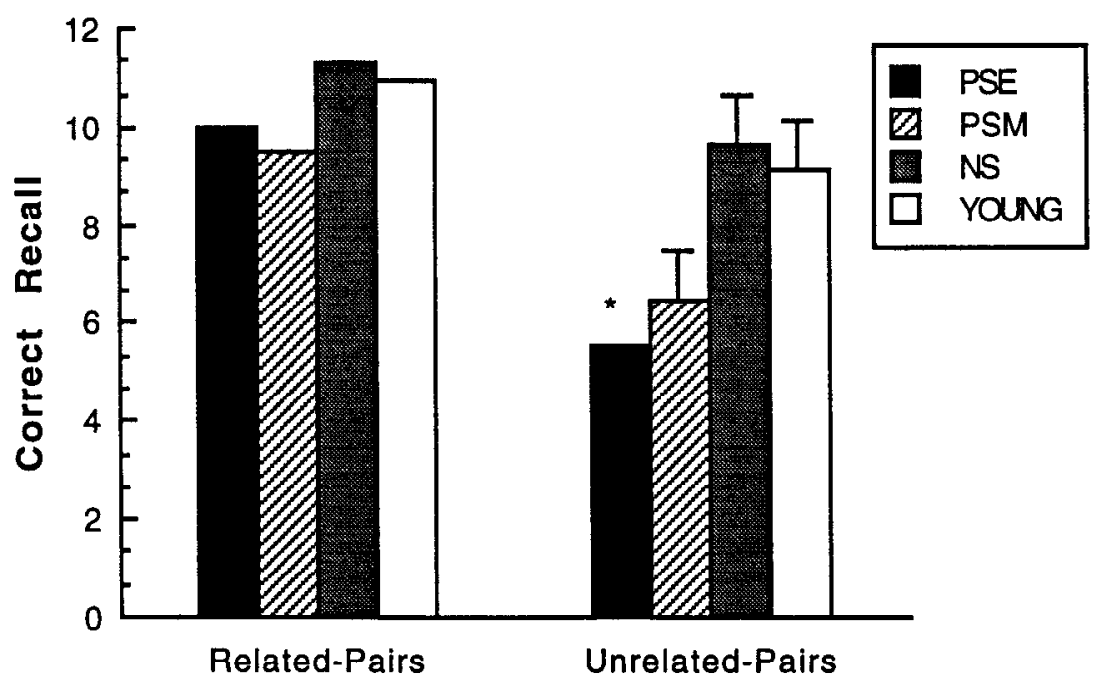

Consequently, in the implicit task, the PSE group gave as many words as the PSM and NS groups.

Selective attention. Errors in the visual search experiment were lower than $3 \%$ for each group and were not subjected to further analysis: A group $\times$ number of items ( 1 vs 4 vs 7 vs 10) $x$ presence (absent- vs present-target) ANOVA applied on median correct $\mathrm{RTs}$ revealed significant main effects of presence $[F(1,16)=93.49 ; p<0.0001]$ and number of items $[F(3,48)=$ $33.37 ; p<0.0001]$ as well as a significant interaction between these two factors $[F(3,48)=4.73 ; p<0.005]$. Analysis of the simple effects performed on this interaction indicated that the effect of number of items on RTs was significant for both absentand present-target trials although it was less pronounced on absent-target trials. A linear regression applied on the pooled results on absent- and present-target trials showed that presenttarget trials gave rise to a linear variation of RTs as a function of the number of stimuli displayed $(r=0.95 ; p<0.05)$ whereas absent-target trials presented a nonlinear variation $(r=0.87 ; p$ $=0.12$ ). This was explainable by the fact that the overall RTs on absent-target trials were longer if only one item was present than if four of more were in the display. Figure 2 presents RTs as a function of number of stimuli and presence of target for the three groups of subjects. The ANOVA also revealed a significant group $\times$ presence interaction $[F(2,16)=4.395 ; p<$ $0.03]$, showing that, although the three groups took equal processing time to respond to present-target trials, the PSE group had significantly higher RTs than the NS group on absent-target trials $(p<0.05)$. As presented in Figure 2, the PSM group fell between the PSE and NS groups with regard to the processing of absent-target trials with a performance closer to that of the PSE group than to that of the NS group.

Comparison with young subjects. Since the performancc of the NS group was better than that of the PSE and PSM groups for both the explicit memory and selective attention tasks (see Figs. 1, 2), two groups of 10 young healthy subjects ( 8 men and 12 women; mean age of $28.3 \pm 6$; mean scolarity of $16.9 \pm$ 3.1) were separately administered the explicit/implicit memory and selective attention tasks in order to be qualitatively compared to subjects of the NS group. Results of the young subjects are represented by the white histograms in Figure 1 and by the dashed line in Figure 2. As shown on these figures, aged subjects from the NS group presented a performance similar to that of these young subjects on both tasks. However, for the implicit memory task, subjects of the NS group performed more poorly than the young subjects.

\section{Discussion}

There was a clear neuropsychological dissociation between explicit and implicit performance in the PSE group, compared to subjects of the PSM and NS groups. Thus, subjects from the PSE group were significantly impaired for the explicit recall of new associations whereas they were not impaired for the explicit recall of preexisting associations and for the implicit memory of both types of association. This neuropsychological dissociation between explicit and implicit performance in the PSE group is similar to that generally observed in amnesic patients showing impaired explicit abilities in the presence of preserved implicit ones (Warrington and Wciskrantz, 1968, 1974; Winocur and Weiskrantz, 1976; Cohen and Squire, 1980; Squire, 1982; Cohen, 1984; Gabrieli et al., 1990; Schacter et al., 1990, 1991). In all these cases, amnesia was the result of temporal lobe excision (Scolville and Milner, 1957) or of hippocampal lesions (Penfield and Milner 1958; Cummings et al., 1984; ZolaMorgan et al., 1986; Victor and Agamanolis, 1990). Thus, the cognitive performance of the PSE group was comparable to that of an amnesic syndrome resulting from hippocampal damage.

Although a significant negative correlation was reported between the cortisol slope and the explicit memory test of Lussier and Peretz (1991), no such correlation was observed with the three subtests of the WMS, which are tests of explicit memory. It could seem puzzling that the cortisol slope was not significantly related with the paired-associated (PA) subtest of the WMS, which is a procedure almost identical to our explicit memory test. However, there are a number of methodological differences between this test and our that could explain this result. First, it may be possible that the PA subtest be less sensitive than our test. For our explicit memory test, and in order to prevent guessing from the subjects, we chose the third associate member of norms associations, while in the PA subtest no such control is made. Second, in the PA subtest, only 4 pairs out of 10 are considered to be unrelated while in our test, an equal number of related and unrelated pairs is provided. In line with this suggestion of a difference in test sensitivity, a study conducted by Lussier et al. (1989) has shown that in normal 


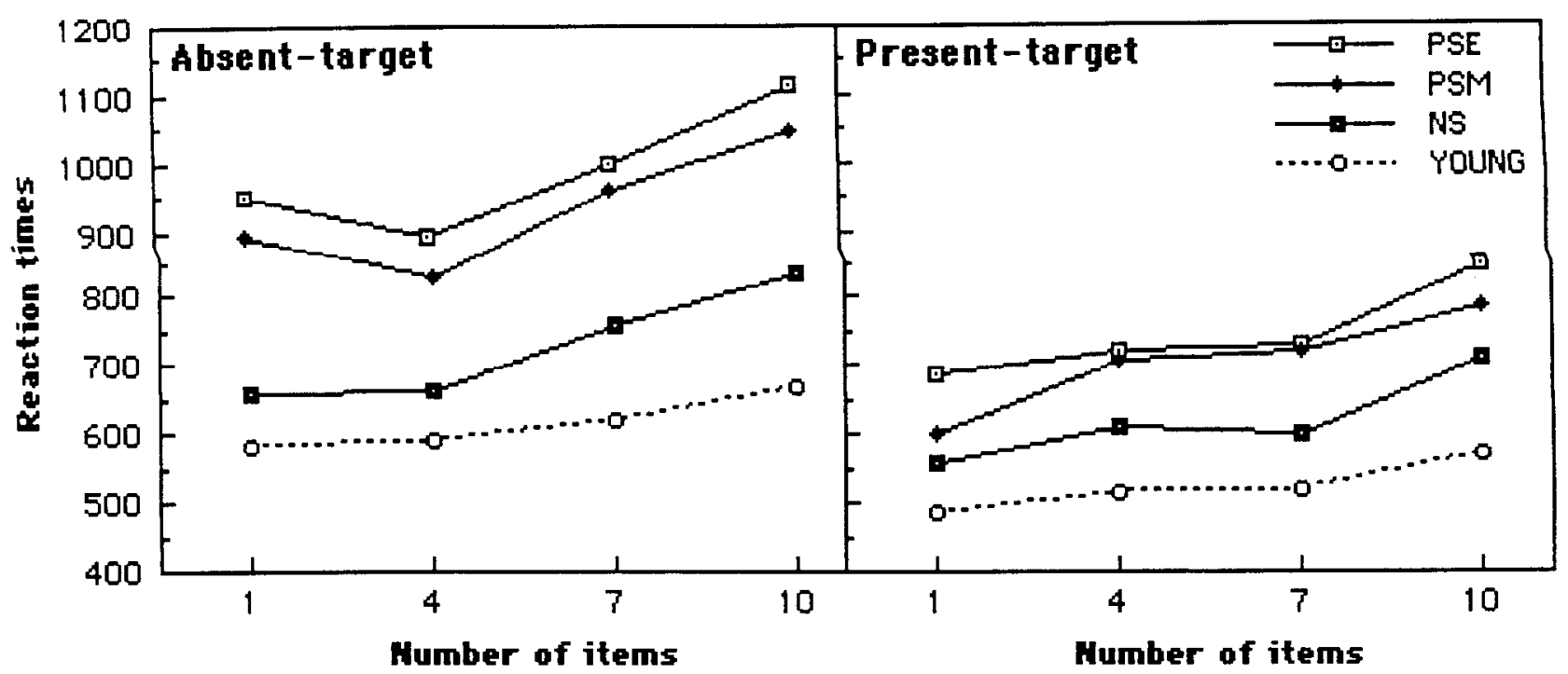

Figure 2. Mean reaction times for the processing of absent- and present-target trials on the visual search task as a function of number of items for subjects of the PSE, PSM, and NS groups and for 10 young healthy subjects.

elderly patients as well as in brain-damaged patients who complained about having memory problems, scores on the explicit memory subtests of the WMS were all in the normal range for elderly and brain-damaged patients (with a ceiling effect for the elderly patients) while on our explicit memory task, which is better controlled in terms of frequency of usage and semantic relatedness, controls did not display a ceiling effect and all patients exhibited an explicit memory deficit to various degrees. Thus, the comparison of scores between these tasks of explicit memory, one widely used in clinical neuropsychology and one inspired from current paradigms used in the experimental study of memory, shows that our task is more sensitive than the explicit memory subtests of the WMS. This difference in task sensitivity could thus explain the significant negative correlation between the cortisol slope and our explicit memory task and the absence of a significant (although negative) correlation with the subtests of the WMS.

The memory results were accompanied by somewhat peculiar findings for the visual search task. It was shown that all three groups of subjects presented intact visual search capacities as revealed by the absence of a group $\times$ number of items interaction. Yet, the only significant effect related to the group factor was that of presence of target. No differences in RTs existed between the three groups with regard to present-target trials whereas the PSE group showed significantly higher RTs on absent-target trials when compared to the NS and the PSM groups. To our knowledge, no indication of such an effect has been reportcd in the visual search literature. However, overall performance differences between present- and absent-target trials have been reported (Farmer and Taylor, 1980; Quinlan and Humphreys, 1987; Cavanagh et al., 1990). These differences indicate that, even though visual search is effective for both kinds of trials, the particular criterion upon which the decision as to the presence or absence of target may vary (see Treisman and Gelade, 1980; Treisman, 1991). Differences in detection strategies could explain the significant presence $x$ number of items interaction reported in the present study. The effect of the number of items on RTs that occurred on absent-target trials suggests that subjects used a strategy in which absent-target responses were based on the homogeneity of the stimulus display. On this account, when four or more stimuli were shown on an absent-target trial, the homogeneity of the display was used by subjects as a signal that the target was absent. Obviously, when only one item was shown on absent-target trials, this homogeneity detection strategy could not apply. In that case, subjects may have had to rely on some explicit identification of the stimulus or on a comparison between it and an internal target template, thus leading to longer RTs (Gordon, 1968; McIntyre et al., 1970; Gordon et al., 1971; Estes, 1972; Prinz, 1977; Shiffrin and Schneider, 1977; Cowan, 1988; Duncan and Humphreys, 1989; Treisman and Sato, 1990; Fisk and Rogers, 1991; Wolfe et al., 1992). The converse of homogeneity detection, which is the detection of heterogeneity (i.e., a discrepant item), did not occur on present-target trials. Indeed, this type of search process should also predict longer RTs with displays of one item than with displays made of four or more items (Arguin et al., 1993). In contrast, the present-target results indicated a linear variation of RTs with the number of items. Since absent-target trials gave rise to significant group differences as opposed to present-target trials, it can be hypothesized that the particular criteria upon which the decision as to absence of target was made was more conservative for the PSE group than for the other two groups. Figure 2 presents RTs for the three groups of subjects as a function of number of stimuli and presence of target. This figure shows that an homogeneity detection strategy was applied by both the PSE and the PSM group, but not by the NS group. Indeed, one-item absent-target gave rise to longer RTs for both the PSE and PSM groups while the NS group presented a linear variation of RTs as a function of number of items for absent-target trials. It is indeed this difference in the processing of the one-item absent-target trials that gave rise to the significant group $\times$ presence interaction. As a matter of fact, eliminating the one-item absent- and presenttarget trials from the ANOVA erased the significant interaction between group and presence of items $[F(2,16)=3.53 ; p>0.05]$, revealing equivalent visual search capacities in all subjects. It 
is clear from these results that more data will be necessary on this topic in order to explain why subjects from the PSE group used such a conservative detection strategy.

The strongest evidence for impaired cognitive function was observed in the PSE subjects. These subjects showed (1) an increase in basal cortisol levels over the past 4 years and (2) elevated current basal cortisol levels (as determined within 6 months or less of neuropsychological testing). The difference in the performance of the NS and PSM groups, which were comparable on recent measures of basal cortisol levels, underscores the importance of the cortisol slope measure. Thus, current basal cortisol levels alone did not predict cognitive impairments, nor did the averaged- $24 \mathrm{hr}$ cortisol mcasurc. Indecd, the best predictor of cognitive impairment was an elevated current basal cortisol level and a trend toward higher basal cortisol levels over time. The significant correlations between cognitive functions and cortisol slope suggest that it is change in cortisol to a higher level which is important.

The increased basal cortisol levels over time observed in the PSE group suggests some degree of HPA dysregulation, perhaps less efficient glucocorticoid negative feedback. The absence of any group difference on the SCL-90 questionnaire (Lupien, Lecours, Schwartz, Sharma, Meaney, and Nair, unpublished observations) suggests that the differences in cortisol levels over time among the groups was not related to differences in life events. Pavlov et al. (1986) have provided evidence for a decrease in glucocorticoid negative feedback sensitivity with age in a normal, healthy population of aged humans. Interestingly, there is evidence for the involvement of the hippocampus in HPA regulation. A considerable number of studies with rodents suggest that glucocorticoids act via both mineralocorticoid and glucocorticoid receptors in the hippocampus to regulate pituitary-adrenal activity (see Jacobson and Sapolsky, 1991, for a review). In the primate, the evidence to date is less compelling, but still very much consistent with the idea that the hippocampus regulates HPA activity. Indeed, fornix transection in monkeys cause basal hypercortisolism (Sapolsky et al., 1991). The involvement of the hippocampus in human HPA regulation is suggested by studies reporting the presence of glucocorticoid receptors in human hippocampus (Sarrieau et al., 1988), and by other studies showing significant correlations between hippocampal atrophy and hypercortisolism (Starkman et al., 1992), or else between age and hypercortisolism in disorders affecting the hippocampus, as in Alzheimer's disease (Davis et al., 1986; DeLeon et al., 1988; Dodt et al., 1991).

The pattern of HPA activity and neuropsychological performance observed in the PSE subjects could be explained, in part at least, by some degree of hippocampal damage. Damage to the hippocampus could result in both the pattern of cognitive deficits and basal cortisol levels over time observed in the PSE subjects. Note, however, that the current basal cortisol levels were also apparently a contributing factor. The differences in the performance between the PSE and PSM subjects suggest that the current basal cortisol levels did affect cognitive performance. It is very likely that, with time, the PSM subjects in the present study will demonstrate progressively impaired performance. This hypothesis will be examined in our ongoing studies.

These findings are consistent with previous rodent studies showing that increased HPA activity predicted the magnitude of hippocampal damage and cognitive impairments (Landfield et al., 1981; Issa et al., 1990). Thus, among aged rats, those animals showing impaired spatial memory also showed in- creased basal glucocorticoid levels. In contrast, aged, cognitively unimpaired animals did not differ from young animals in HPA activity (see also Levin et al., 1992; Sarrieau et al., 1992). These authors further showed that while aged, cognitively unimpaired rats exhibited basal HPA activity similar to young animals, there was a depletion of hippocampal neurons in all the older animals. These data demonstrated that HPA dysfunction can predict the cognitive and neuropathological variations in the aging process, although neuron loss is not the only indicator of spatial learning deficit in the rats (also see McEwen, 1992; Meaney et al., 1993). In humans, reports show that in many conditions associated with elevated corticosteroid levels and cerebral atrophy [e.g., in Cushing's syndrome, glucocorticoid therapy, etc. (Momose et al., 1971; Bentson et al., 1978; Okuno et al., 1980)], a lowering of the dosage or a withdrawal of treatment altogether reverses the steroid-induced atrophy (Bentson et al., 1978; Okuno et al., 1980; Starkman et al., 1992) and the cognitive disturbances (Ling et al., 1981). Thus, corticosteroids can cause cognitive deficits via a mechanism that is independent of hippocampal neuron loss.

Such a mechanism has been described in studies showing that corticosterone suppresses hippocampal excitability and LTP (Bliss and Lomo, 1973; Gustafsson and Wigstrom, 1988) in a concentration dependent manner (Pfaff et al., 1971; Michal, 1974; Segal, 1976; Reiheld et al., 1984; Vidal et al., 1986; Foy et al., 1987; Bennett et al., 1991). More recently, Bodnoff, Diamond, Rose, and Meaney (unpublished observations) have shown that the learning deficits observed in aged rats exposed for 3 months to medium levels of corticosterone could not be explained by hippocampal neuron loss, but rather by a vulnerability in hippocampal function, as revealed by a reduced level of LTP in the hippocampus of the treated animal. These results were similar to those reported by Deupree et al. (1991) showing a correspondence between impaired performance in the Morris water maze and significantly reduced LTP. The cognitive results of subjects from the PSE group, which showed significant elevation of corticosteroids with years and presented explicit memory deficits, could thus be in accordance with the hypothesis that glucocorticoids can alter synaptic plasticity within the hippocampus rather than/or before giving rise to neuron loss (see Kerr et al., 1991). Indeed, although subjects from the PSE group presented impaired cognitive performance when compared to the other aged subjects, it has to be said that these cognitive deficits were subclinical. It can be suggested from these results that significant elevation of cortisol levels with years results in hippocampal dysfunction and mild cognitive impairments. If a certain threshold of hippocampal dysfunction is reached, it can be postulated that neuron loss will occur that will be related to more severe cognitive deficits. A neuropsychological reassessment of the aged subjects reported in this study will thus be necessary in order to confirm this hypothesis.

\section{References}

Arguin M, Joanette Y, Cavanagh P (1993) Visual search for feature and conjunction targets with an attention deficit. J Cognit Neurosci 5: $436-452$.

Bennett MC, Diamond DM, Fleshner M, Rose GM (1991) Serum corticosterone level predicts the magnitude of hippocampal primed burst potentiation and depression in urethane-anesthetized rats. Psychobiology 19:301-307.

Bentson J, Reza M, Winter J, Wilson G (1978) Steroids and apparent cerebral atrophy on computed tomography scans. J Comput Assist Tomogr 2:16-23.

Bliss TVP, Lomo T (1973) Long-lasting potentiation of synaptic trans- 
mission in the dentate area of the anaesthetized rabbit following stimulation of the perforant path. J Physiol (Lond) 232:331-356.

Butters N, Heindel WC, Salmon DP (1990) Dissociation of implicit memory in dementia: neurological implications. Bull Psychonom Soc 28:359-366.

Cavanagh P, Arguin M, Treisman A (1990) Effect of stimulus domain on visual search for orientation and size features. J Exp Psychol [Hum Percept] 16:479-491.

Cohen J, Cohen P (1983) Applied multiple regression/correlation analysis for the behavioral sciences, $2 d$ ed. Hillsdale, NJ: Erlbaum.

Cohen NJ (1984) Preserved learning capacity in amnesia: evidence for multiple systems. In: Neuropsychology of memory (Squire LR, Buttcrs N, cds), pp 83-103. Ncw York: Guilford.

Cohen NJ, Squire LR (1980) Preserved learning and retention of pattern analyzing skill in amnesia: dissociation of knowing how and knowing that. Science 210:207-209.

Cohen RM, Weingartner H, Smallberg S, Pickar D, Murphy DL (1982) Effort and cognition in depression. Arch Gen Psychiatry 39:593-597.

Colucci CF, D'Alessandro B, Bellastella A, Montalbetti N (1975) Circadian rhythm of plasma cortisol in the aged (Cosinor method). Geront Clin 17:89-95.

Cowan N (1988) Evolving conceptions of memory storage, selective attention, and their mutual constraints within the human information-processing system. Psychol Bull 104:163-191.

Craik FIM (1977) Age differences in human memory. In: Handbook of the psychology of aging (Birren JE, Schaie KW, eds), pp 384-420. New York: Van Nostrand Reinhold.

Cummings JL, Tomiyasu U, Read S, Benson DF (1984) Amnesia with hippocampal lesions after cardiopulmonary arrest. Neurology 34:679681.

Davis KL, Davis BM, Greenwald BS, Mohs RC, Mathé AA, Johns CA, Horvath TB (1986) Cortisol and Alzheimer's disease. I. Basal studies. Am J Psychiatry 143:300-305.

DeLeon M, McRae T, Tsai J, George A, Marcus D, Freedman M, Wolf A, McEwen B (1988) Abnormal cortisol response in Alzheimer's disease linked to hippocampal atrophy. Lancet 2:391-392.

Deupree DL, Turner DA, Watters CL (1991) Spatial performance correlates with in vitro potentiation in young and aged Fischer 344 rats. Brain Res 554:1-9.

Diamond DM, Bennett MC, Fleshner M, Rose GM (1992) Inverted-U relationship betwecn the level of peripheral and the magnitude of hippocampal primed burst potentiation. Hippocampus 2:421-430.

Dodt C, Dittmann J, Hruby J, Spath-Schwalbe E, Born J, Schuttler R, Fehm HL (1991) Different regulation of adrenocorticotropin and cortisol secretion in young, mentally healthy elderly and patients with senile dementia of Alzheimer's type. J Clin Endocrinol Metab 72: 272-276.

Duncan J, Humphreys G (1989) A resemblance theory of visual search. Psychol Rev 96:433-458.

Estes WK (1972) Interactions of signal and background variables in visual processing. Percept Psychophys 12:278-286.

Farmer EW, Taylor RM (1980) Visual search through color displays: effects of target-background similarity and background uniformity. Percept Psychophys 27:267-272.

Fisk AD, Rogers WA (1991) Toward an understanding of age-related memory and visual search effects. J Exp Psychol [Gen] 120:131-149.

Foy MR, Stanton ME, Levine S, Thompson RF (1987) Behavioral stress impairs long-term potentiation in rodent hippocampus. Behav Neural Biol 48:138-149.

Freibergs VV (1968) Normes d'Association Libre aux 100 mots de Kent-Rosanoff, étude des réseaux associatifs; Rapport 1. Université de Montréal.

Freibergs VV (1970) Normes d'Association Libres aux Cinq premières réponses aux 100 mots de Kent-Rosanoff, étude des réseaux associatifs; Rapport 2. Université de Montréal.

Friedman M, Green MF, Sharland DE (1969) Assessment of hypothalamic-pituitary-adrenal function in the geriatric age group. J Gerontol 24:292-297.

Gabrieli JDE, Milberg W, Keane MM, Corkin S (1990) Intact priming of patterns despite impaired memory. Neuropsychologia 28:417-427.

Gaffan D (1974) Recognition impaired and association intact in the memory of monkeys after transection of the fornix. J Comp Physiol Psychol 86:1100-1109.

Gordon IE (1968) Interactions between items in visual search. J Exp Psychol 76:348-355.
Gordon IE, Dulewicz V, Winwood M (1971) Irrelevant item variety and visual search. J Exp Psychol 88:295-296.

Graf P, Schacter DL (1985) Implicit and explicit memory for new associations in normal and amnesic subjects. J Exp Psychol [Hum Learn] 13:45-53.

Gustafsson B, Wigstrom H (1988) Physiological mechanisms underlying long-term potentiation. Trends Neurosci 11:156-162.

Hall RC, Popkin MK, Stickney SK, Gardner ER (1979) Presentation of the steroid psychoses. J Nerv Ment Dis 167:229-236.

Hirsh R (1974) The hippocampus and contextual retrieval of information from memory: a theory. Behav Biol 12:421-444.

Issa AM, Rowe W, Gauthier S, Meaney MJ (1990) Hypothalamicpituitary-adrenal activity in aged, cognitivcly impaircd and cognitively unimpaired rats. J Neurosci 10:3247-3254.

Jacobson L, Sapolsky R (1991) The role of the hippocampus in feedback regulation of the hypothalamic-pituitary-adrenocortical axis. Endocr Rev 12:118-134.

Jensen BA, Sanders S, Frolund B, Hjortrup A (1988) Adrenocortical function in old age as reflected by plasma cortisol and ACTH test during the course of acute myocardial infarction. Arch Gerontol Geriat 7:289-296.

Jensen HK, Blichert-Toft M (1971) Serum corticotrophin plasma cortisol and urinary excretion of 17-ketogenic steroids in the elderly (age group: 66-94 years). Acta Endocrinol 66:25-34.

Joels M, DeKloet ER (1989) Effects of glucocorticoids and norepinephrine on the excitability in the hippocampus. Science 245:15021505.

Kerr DS, Campbell LW, Hao S-Y, Landfield PW (1989) Corticosteroid modulation of hippocampal potentials: increased effect during aging. Science 245:1502-1505.

Kerr DS, Campbell LW, Applegate MD, Brodish A, Landfield PW (1991) Chronic stress-induced acceleration of electrophysiologic and morphometric biomarkers of hippocampal aging. J Neurosci 11:13161324.

Kopell BS, Willner WK, Landi D, Warrick G, Edwards D (1970) Cortisol effects on averaged evoked potentials, alpha-rhythm, time estimation, and two-flash fusion threshold. Psychosom Med 32:39-49.

Lachman R, Lachman JL (1980) Picture naming: retrieval and activation of long-term memory. In: New directions in memory and aging (Poon LW, Fozard JL, Cermak LS, Arenberg D, Thompson LW, eds), pp 313-344. Hillsdale, NJ: Erlbaum.

Lakatua DJ, Nicolau GY, Bogdan C, Petrescu E, Sackett-Lundeen LL, Irvine PW, Haus E (1984) Circadian endocrine time structure in humans above 80 years of age. J Gerontol 39:648-654.

Landfield PW, Baskin RW, Pitler TA (1981) Brain-aging correlates: retardation by hormonal-pharmacological treatments. Science 214: 581-584.

Levin N, Bengani N, Rowe W, Meaney MJ, Roberts JL (1992) Elevated anterior proopiomelanocortin (POMC) gene expression at lights off in aged rats with spatial memory impairment. Soc Neurosci Abstr 18:668.

Ling M, Perry P, Tsuang M (1981) Side effects of corticosteroid therapy. Arch Gen Psychiatry 38:471-477.

Linkowski P, Mcndlcwicz J, Lcclercq R, Brasseur M, Hubain P, Golstein J, Copinschi G, Van Cauter E (1985) The 24-hour profile of adrenocorticotropin and cortisol in major depressive illness. J Clin Endocrinol Metab 61:429-438.

Lussier I, Peretz I (1991) La mémoire en boîtes. Rev Neuropsychol $1: 327-342$

Lussier I, Peretz I, Belleville S, Fontaine F (1989) Contribution of indirect measures of memory to clinical neuropsychology assessment. J Clin Exp Neuropsychol 11:64.

Lyons J (1976) Semantics, 12. Cambridge: Cambridge UP

Martignoni E, Petraglia F, Costa A, Bono G, Genazzani AR, Nappi G (1990) Dementia of the Alzheimer type and hypothalamus-pituitaryadrenocortical axis: changes in cerebrospinal fluid, corticotropin releasing factor and plasma cortisol levels. Acta Neurol Scand 81:452456.

Martignoni E, Costa A, Sinforiani E, Liuzzi A, Chiodini P, Mauri M, Bono $G$, Nappi $G$ (1992) The brain as a target for adrenocortical steroids: cognitive implications. Psychoneuroendocrinology 17:343354.

McEwen BS (1992) Re-examination of the glucocorticoid hypothesis of stress and aging. In: Progress in brain research, Vol 93 (Swaab DF, 
Hofman MA, Mirmiran M, Ravid R, van Leebwen FW, eds), pp 365383. Amsterdam: Elsevier.

McIntyre C, Fox R, Neale J (1970) Effects of noise similarity and redundancy on the information processed form brief visual displays. Percept Psychophys 7:328-332.

Meaney MJ, Bodnoff SR, O'Donnell D, Rowe W, Sarrieau A, Rose GM, Poirier J, Seckl J (1993) Glucocorticoids as regulators of neuron survival and repair in the aged brain. In: Restorative neurology, Vol 6 (Cuello AC, ed), pp 185-210. Amsterdam: Elsevier.

Mehler J (1981) The syllable's role in speech segmentation. J Verb Learn Verb Behav 20:298-305.

Metz-Lutz MN, Kremin H, Deloche G, Hannequin D, Ferrand I, Perrier D, Quint S, Dordain M, Bunel G, Cardebat D, Larroque C, Lota AM, Pichard B, Blavier A (1991) Standardisation d'un test de dénomination orale: contrôle des effets de l'âge, du sexe et du niveau de scolarité chez les sujets adultes normaux. Rev Neuropsychol 1:7395.

Michal EK (1974) Dexamethasone inhibits multi-unit activity in the rat hippocampus. Brain Res 65:180-183.

Momose KJ, Kjellberg RN, Kliman B (1971) High incidence of cortical atrophy of the cerebral and cerehellar hemispheres. Radiology 99: 341-348.

Okuno T, Ito M, Yoshioka M, Nakano Y (1980) Cerebral atrophy following ACTH therapy. J Comput Assist Tomogr 4:20-23.

Oxenkrug GF, Gurevich D, Siegel B, Dumiao MS, Gershon S (1989) Correlation between brain-adrenal axis activation and cognitive impairment in Alzheimer's disease: is there a gender effect? Psychiatry Res 29:169-175.

Pavlov EP, Harman SM, Chrousos GP, Loriaux DL, Blackman MR (1986) Responses of plasma adrenocorticotropin, cortisol, and dehydroepiandrosterone to ovine corticotropin-releasing hormone in healthy aging men. J Clin Endocrinol Metab 62:767-772.

Penfield W, Milner B (1958) Memory deficit produced by bilateral lesions in the hippocampal zone. Arch Neurol Psychiatry 79:475497.

Pfaff DW, Silva MTA, Weiss JM (1971) Telemetered recording of hormone effects on hippocampal neurons. Science 172:394-395.

Prinz W (1977) Memory control of visual search. In: Attention and performance, Vol VI (Dornic S, ed), pp 441-463. New York: Erlbaum.

Quinlan PT, Humphreys GW (1987) Visual search for targets defined by combinations of color, shape, and size: an examination of the task constraints on feature and conjunction searches. Percept Psychophys 41:455-472.

Rabbitt PMA (1964) Ignoring irrelevant information. Br J Psychol 55:403-414.

Reiheld CT, Teyler TJ, Vardaris RM (1984) Effects of corticosterone on the electrophysiology of hippocampal CA1 pyramidal cells in vitro. Brain Res Bull 12:349-353.

Rosen WG (1980) Verbal fluency in aging and dementia. I Clin Neuropsychol 2:135-146.

Roy-Byrne PP, Weingartner H, Bierer LM, Thompson K, Post RM (1986) Effortful and automatic cognitive processes in depression. Arch Gen Psychiatry 43:265-267.

Rubinow D, Post R, Savard R, Gold P (1984) Cortisol hypersecretion and cognitive impairment in depression. Arch Gen Psychiatry 41: 279-283.

Sabourin L (1988) Processus lexico-sémantiques et hémisphère droit: êtude de la fluence verbale à partir de critères formels et sémantiques. Université de Montréal, Mémoire.

Sapolsky R, Zola-Morgan S, Squire L (1991) Inhibition of glucocorticoid secretion by the hippocampal formation in the primate. J Neurosci 11:3695-3704.

Sarrieau A, Sharma S, Meaney MJ (1988) Postnatal development and environmental regulation of hippocampal glucocorticoid and mineralocorticoid receptors in the rat. Dev Brain Res 43:158-162.

Sarrieau A, Rowe W, O'Donnell D, LaRocque S, Nair NPV, Levin N, Seckl JR, Meaney MJ (1992) Hypothalamic-pituitary-adrenal activity and corticosteroid receptor expression in aged, cognitively-impaired and cognitively-unimpaired rats. Soc Neurosci Abstr 18:669.

Schacter DL (1987) Implicit memory: history and current status. J Exp Psychol [Hum Learn] 13:501-518.

Schacter DL, Delaney SM, Merikle EP (1990) Priming of nonverbal information and the nature of implicit memory. In: The psychology of learning and motivation, Vol 26 (Bower G, ed), pp 83-123. San Diego: Academic.
Schacter DL, Cooper LA, Tharan M, Rubens AB (1991) Preserved priming of novel objects in patients with memory disorders. J Cognit Neurosci 3:117-130.

Scolville WB, Milner B (1957) Loss of recent memory after bilateral hippocampal lesions. J Neurol Neurosurg Psychiatry 20:11-21.

Segal M (1976) Interactions of ACTH and norepinephrine on the activity of rat hippocampal cells. Neuropharmacology 15:329-333.

Sharma M, Palacios-Bois J, Schwartz G, Iskandar H, Thakur M, Quirion M, Nair NPV (1989) Circadian rhythms of melatonin and cortisol in aging. Biol Psychiatry 25:305-319.

Sherman B, Wysham C, Pfohl B (1985) Age-related changes in the circadian rhythm of plasma cortisol in man. J Clin Endocrinol Metab 61:439-443.

Shiffrin RM, Schneider W (1977) Toward a unitary model for selective attention, memory scanning, and visual search. In: Attention and performance, Vol VI (Dornic S, ed), pp 413-438. New York: Erlbaum.

Squire LR (1982) The neuropsychology of human memory. Annu Rev Neurosci 5:241-273.

Squire LR (1987) Memory and brain. New York: Oxford UP.

Squire LR (1992) Memory and the hippocampus: a synthesis from findings with rats, monkeys, and humans. Psychol Rev 99:195-231.

Starkman MN, Gebarski SS, Berent S, Schteingart DE (1992) Hippocampal formation volume, memory dysfunction, and cortisol levels in patients with Cushing's syndrome. Biol Psychiatry 32:756-765.

Thompson RF (1986) The neurobiology of learning and memory. Science 233:941-947.

Treisman A (1982) Perceptual grouping and attention in visual search for features and for objects. J Exp Psychol [Hum Percept] 8:194-214.

Treisman A (1983) The role of attention in object perception. In: Physical and biological processing of images (Braddick OJ, Sleigh AC, eds), pp 316-325. New York: Springer.

Treisman A (1991) Search, similarity, and integration of features between and within dimensions. J Exp Psychol [Hum Percept] 17:652676.

Treisman A, Gelade $G$ (1980) A feature-integration theory of attention. Cognit Psychol 12:97-136.

Treisman A, Sato S (1990) Conjunction search revisited. J Exp Psychol [Hum Percept] 16:459-478.

Varney NR, Alexander B, MacIndoe JH (1984) Reversible steroid dementia in patients without steroid psychosis. Am J Psychiatry 141: 369-372.

Victor M, Agamanolis D (1990) Amnesia due to lesions confined to the hippocampus: a clinical-pathologic study. J Cognit Neurosci 2:246257.

Vidal C, Jordan W, Zieglgansberger W (1986) Corticosterone reduces the excitability of hippocampal pyramidal cells in vitro. Brain Res 383:54-59.

Waltman C, Blackman MR, Chrousos GP, Riemann C, Harman SM (1991) Spontaneous and glucocorticoid-inhibited adrenocorticotropic hormone and cortisol secretion are similar in healthy young and old men. J Clin Endocrinol Metab 73:495-502.

Warrington EK, Weiskrantz L (1968) New method of testing longterm retention with special reference to amnesic patients. Nature 217: 972-974.

Warrington EK, Weiskrantz L (1974) The effect of prior learning on subsequent retention in amnesic patients. Neuropsychologia 12:419428.

Wechsler DA (1969) Manuel de l'échelle clinique de mémoire de D. Wechsler. Paris: Editions du Centre de Psychologie Appliquée.

Weingartner H, Cohen RM, Martello J (1981) Cognitive processes in depression. Arch Gen Psychiatry 38:42-47.

Weitzman ED, Fukushima D, Nogeire C, Roffwarg H, Gallagher TF, Hellman L (1971) Twenty-four hour pattern of the episodic secretion of cortisol in normal subjects. J Clin Endocrinol 33:14-22.

West CD, Brown H, Simon EL, Carter DB, Kumagai LF, Englert E (1961) Adrenocortical function and cortisol metabolism in old agc. J Clin Endocrinol Metab 21:1197-1207.

Winocur G, Weiskrantz L (1976) An investigation of paired-associate learning in amnesic patients. Neuropsychologia 14:97-110.

Wolfe JM, Friedman-Hill SR, Stewart MI, O'Connell KM (1992) The role of categorization in visual search for orientation. J Exp Psychol [Hum Percept] 18:34-39.

Wolkowitz OM, Rapaport M (1989) Long-lasting behavioral changes following prednisone withdrawal. J Am Med Assoc 261:1731-1732.

Wolkowitz OM, Weingartner H (1988) Defining cognitive changes in 
depression and anxiety: a psychobiological analysis. Psychiatr Psychobiol 3:1315-1385.

Wolkowitz OM, Reus VI, Weingartner H, Thompson K, Breier A, Doran A, Rubinow D, Pickar D (1990) Cognitive effects of corticosteroids. Am J Psychiatry 147:1297-1303.

Zola-Morgan S, Squire LR, Amaral DG (1986) Human amnesia and the medial temporal region: enduring memory impairment following a bilateral lesion limited to field $\mathrm{CA}_{1}$ of the hippocampus. J Neurosci 6:2950-2967.

Zumoff B, Fukushima DK, Weitzman ED, Kream J, Hellman L (1974) The sex difference in plasma cortisol concentration in man. $J$ Clin Endocrinol Metab 39:805-808. 